\title{
There is no Fallacy of Arguing from Authority
}

\author{
EDWIN COLEMAN University of Melbourne
}

Keywords: fallacy, argument, authority, speech act.

\begin{abstract}
I argue that there is no fallacy of argument from authority. I first show the weakness of the case for there being such a fallacy: text-book presentations are confused, alleged examples are not genuinely exemplary, reasons given for its alleged fallaciousness are not convincing. Then I analyse arguing from authority as a complex speech act. Rejecting the popular but unjustified category of the "part-time fallacy", I show that bad arguments which appeal to authority are defective through breach of some felicity condition on argument as a speech act, not through employing a bad principle of inference.
\end{abstract}

\section{Introduction/Summary}

There's never been a satisfactory theory of fallacy, as Hamblin pointed out in his book of 1970 , in what is still the least unsatisfactory discussion. Things have not much improved in the last 25 years, despite fallacies getting more attention as interest in informal logic has grown. We still lack good answers to simple questions like what is a fallacy?, what fallacies are there? and how should we classify fallacies?

The idea that argument from authority (argumentum ad verecundiam) is a fallacy, is well-established in logical tradition. I argue that it is no such thing. The second main part of the paper is negative: I show the weakness of the case made in the literature for there being such a fallacy as argument from authority. First, text-book presentation of the fallacy is confused, second, the examples given are not genuinely exemplary and third, reasons given for its alleged fallaciousness are not convincing. Fourth, attempts to improve on the text-book accounts in recent literature are not much help. The third main part is positive: I propose that consideration of arguing from authority as a complex speech act illuminates existing discussion and points toward a clear and simple positive argument for there being no such fallacy. Specifically, I suggest that such an analysis enables us to reject the unjustified category of the "part-time fallacy" (which has increasingly shown up in texts recently), by showing that bad arguments which appeal to authority are defective through breach of some felicity condition on argument as a speech act rather than through employing a bad principle of inference. The variety of ways such an argument can go wrong reflects the complex structure of felicity conditions on it, not a long and unprincipled list of unexpressed premises, as some authors have argued. Arguing from authority uses a good principle of inference: after all, some arguments of this kind are good. There is no fallacy of argument from authority. 


\section{The weakness of the case for there being a fallacy}

It is commonly said that argument from authority is a fallacy, and a fallacy is generally said to be a type of argument which seems good but is not'. Now an argument (in this sense) can be bad in two ways, through having a false or unacceptable premise or through having a bad inference. Many logicians put aside the unacceptable premises with the sense of 'fallacy' as a false belief, emphasising logic's concern with inference. It is having a defective inference that makes a fallacy bad; it is a bad type of argument. To say that the inference of an argument is bad is to say that the premises give no support to the conclusion. So a fallacy is a type of argument whose premises, even if true, give no support to the conclusion, though they may seem to. (Some informal logicians do want to treat false premises as sources of fallacy, and I will discuss some below; I think this is a mistake and give some argument against it, but this paper is mainly intended to counter the idea that arguing from authority is a fallacy in the narrower sense just given.)

The argument from authority is this kind of argument:

Aristotle says that the earth does not move, so the earth does not move.

But this form

A says p. so $p$

is not worth using instead of the plain assertion

$p$

unless challenges like 'who's A?' or 'how would A know?' can be met with a response giving some kind of credential to $A$. So $I$ think it is reasonable to say that this form is enthymematic, that there is a standard omitted premise and that the form of the argument should be taken as

A says $p$. A is authoritative on such things, so $p$

These days expertise is as often taken as authority so we may also put it

E says $p . E$ is expert on $p$, sop

\section{[a] Confused Presentation}

Most authors these days grant that some appeals to authority are legitimate, which may seem to suggest that I am beating on an open door: few current authors are so incautious as to claim that there is a fallacy of arguing from authority simpliciter. However things are not so simple. Writers on fallacy still mostly manage to convey the message that argument from authority is a bad thing.

Older logic books unabashedly declare there is a fallacy of argumentum ad verecundiam, or appealing to authority; but judging from their ways of presenting their discussions, it seems that many authors are rather uncertain that there really is a fallacy. The better recent books tend to imply that there is such a fallacy by their section headings but to say in their discussion that appealing to authority is "sometimes a fallacy." The notion of a part-time fallacy is not much discussed, but some have marked this shift by referring instead to the fallacy of appealing to 
inappropriate authority, or something similar. For example, Copi's Introduction to logic, second edition [1961] has "Argumentum ad verecundiam (appeal to authority)" as a section heading, in a chapter labelled "Informal fallacies", but says in the body of the text "This method of argument is not always strictly fallacious". Perhaps he means that it is sometimes loosely fallacious; but as to what a loosely fallacious argument is, no hint is given. In the eighth edition [Copi and Cohen, 1990] by contrast, the section heading has become "The appeal to inappropriate authority - argumentum ad verecundiam". This is nowadays quite a common tack. Good authors also can be found listing not one but various kinds of fallacious argument from authority; only they rarely agree on what kinds there are or what makes them fallacious. For example, having pointed out earlier on that many appeals to authority are legitimate, Barry and Rudinow [1989] distinguish a variety of "fallacious" ways to appeal to authority, but under a heading "Appeal to authority" in a chapter called "Informal fallacies of relevance". Similarly Engel [1986: $212 \mathrm{ff}]$ has a big heading "The fallacy of appeal to authority" which clearly implies that just appealing to authority is fallacious. But in the body text he immediately says that "appeals to authority are often valid [sic], as when we tell someone to use a certain medicine because the doctor prescribed it."

The impression given by the way the alleged fallacy is introduced in these and most other recent logic texts is that arguing from authority is fallacious really, but there are exceptions-rather as in the $19^{\text {th }}$ century some mathematicians used to talk about theorems with exceptions.

\section{[b] The Examples in Text Books Don't Exemplify}

Barry and Rudinow [1990: 233ff] give examples which differentiate what they call six "varieties of this fallacy", as follows.

[1] "Invincible authority. When an appeal to authority wipes out all other considerations, it constitutes a fallacious appeal to authority." They give an example from Galileo:

But can you doubt that air has weight when you have the clear testimony of

Aristotle affirming that all the elements have weight including air, and excepting only fire?

The argument they seem to have in mind here is the air has weight since Aristotle says the air has weight [and Aristotle is never wrong]. Galileo does not actually give this second premise, but since no authority is indefeasible, if this were the argument Galileo intended, then his argument has a false premise, not a bad inference. If Aristotle were never wrong, this argument would be fine.

What in any case do they mean when they say "when an appeal to authority wipes out all other considerations"? In explication they point to religious groups like the Jonestown group who committed suicide at their leader's behest. It was no doubt highly irrational of these people to believe everything Jim Jones said, but it is inaccurate to imply that Jones made an irrelevant appeal to authority in suggesting they commit suicide. In fact he used his own authority, no doubt stupidly or madly or evilly, but he did not appeal to it. If someone else made the 
claim 'everything Jim Jones says is so' this wa's simply making a false claim. It cannot be the type of argument that wipes out all other considerations but rather the blame is on the participants' attitudes to Jones, to arguments etc. Fallacy is not necessarily involved just because irrationality is.

So, if the type of argument intended here is characterised by a premise of the kind 'everything $X$ says is so' its fault is just having a false premise; but if the fault adverted to is blind faith, that is no fallacy either.

[2] "Irrelevant expertise. When the appeal is to an authority whose expertise is in some field other than the one at issue, the appeal is to irrelevant expertise. For example, quoting the political or economic opinions of a distinguished physicist like Oppenheimer or Einstein is fallacious because the massive weight of an Einstein's opinion in the field of physics may not transfer to other fields."

Here again the problem is a simple mistaken belief - that Einstein is authoritative about politics; not a mistaken inference of appealing to authority. (Incidentally to say that Einstein's views about politics should not be given weight just because he is an expert on physics, clearly presupposes that appeal to a genuine authority is fine.) example:

[3] The third kind of example they give is so-called testimonials, for

Don Meredith for Lipton's tea: "What makes me a Lipton's tea lover? Lipton tastes so damn good."

As it stands, there is no argument here, so no fallacy. To invent an argument equivalent to the ad we might try something like You should drink Lipton's tea, because Don Meredith says it's good and we will have to impute to the advertisers the implied premise If tea tastes good to Don Meredith it will taste good to you. Thus the idea is that the ad is equivalent to the argument

Lipton's tea tastes good to Don Meredith

If tea tastes good to Don Meredith it will taste good to you, so

You should drink Lipton's tea.

The artificiality and lack of real equivalence of the result is obvious. It derives from trying to find in the ad an attempt to prove something, as though the advertisers want to prove that Lipton's tea is good, and offer as evidence Don's statement. But an ad is not an attempt at proof; this one is really urging:

Be like Don Meredith, drink Lipton's tea.

If Don Meredith, whoever he is, says Lipton's tea tastes good to him, then if true, this might be a good reason for my drinking it if I want to ape him, or might not, if I don't. Most likely it's simply a lie. If there is something wrong here it is it is his lying or the advertisers' wrongly thinking I want to ape him, not a mistaken inference. Nobody believes the imputed premise and there is no reason to impute it because there is not even an attempt at argument, so how can there be a fallacy?

[4] "Unidentified experts. Frequently expert opinion is merely alluded to, or is identified in such a vague or incomplete way that its reliability, accuracy, and weight are impossible to verify...phrases like "experts agree"." The example they give is 


\section{Doctors recommend one pain reliever most: the one you get in Anacin.}

This is a pretty bad example because the main thing wrong here is the misleading implication that the pain reliever in question, namely aspirin, is only found in Anacin. If we remove this distraction we get

Doctors recommend one pain reliever most: Anacin.

This is no longer a real example and probably no longer true, but never mind: is it a fallacy?

It is not yet an argument, so let's make it one:

Doctors recommend one pain reliever most: Anacin. So Anacin is best.

Now this is certainly not a very good argument for the very simple reason that the term 'doctors' is too vague. But

Most physicians recommend one pain reliever most: Anacin. So Anacin is best. would be a (fairly) good argument if the premise were true, and it isn't good just because that premise is false. On the other hand

Most physicians recommend one pain reliever most: aspirin. So aspirin is best. is not an argument for the conclusion wanted although it is an acceptable though weak argument from authority. But even then it is weak because we have 'most physicians' not' 'all physicians '. Neither version is bad because it appeals to authority.

[5] "Experts with axes to grind. Sometimes claims are advanced by appeal to experts who do have impressive and genuinely relevant credentials, but whose testimony may legitimately be suspected due to demonstrable conflict of interest...Suppose our attention is directed to an inconclusive study of the effects of second-hand tobacco smoke conducted at a reputable institution under the direction of someone with genuine scientific credentials. Now suppose we learn that the study was underwritten by a research grant supplied by the Tobacco Institute. We should at least look for other studies to compare this one with."

I agree entirely with the conclusion here. Only I don't see what fallacy is being alluded to. Incidentally it is noteworthy that discussions of this "fallacy" generally go in for these vague descriptions rather than concrete examples. Presumably the idea intended here is that someone might say

Expert E says passive smoking is harmless, so passive smoking is harmless where $E$ is the recipient of the dubious funding. (Of course, no-one would actually say

$E$ says smoking is harmless and $E$ is an expert but $E$ has a financial interest in people believing smoking is harmless, so smoking is harmless.

If the third premise is left out the argument might well be contested by pointing it out; but that shows that it is part of the opposite case not of this argument.) But there may well be nothing wrong with an argument of this kind even when such a clause is true: most proponents of theories have an interest in other people believing them, even physicists. We don't ignore Einstein's views in physics because it was to his advantage to become a widely respected physicist.

If there is something wrong with the argument it must boil down to the fact that $\mathrm{E}$ says passive smoking is harmless but $E$ is lying because $\mathrm{E}$ knows the 
evidence is bogus. After all there are always perfectly proper studies which give evidence for or against anything you like.

This example is one where a presupposition of appealing to authority fails, namely the sincerity of the cited authority; but that is not the same thing as a fallacy being committed. There is no fallacy here if a fallacy is a bad type of argument. The type of argument is appealing to authority, which is a good type of argument; only in this instance it has been badly executed. I will enlarge on this contrast in the second part of the paper.

[6] "Division of expert opinion... When the experts disagree, citing the authority of representatives of one side or the other fails to settle the issue and constitutes a fallacy". They mention controversy about how AIDS spreads and say "In such a climate of controversy it would be inadequate simply to quote [one expert]".

This is a peculiar way to deal with a genuine problem which has been widely discussed in the literature (for example Willard 1990, Cederblom and Paulsen 1988). Indeed for some writers this is the only real problem about argument from authority. Once again Barry and Rudinow do not give an actual example of an argument committing a fallacy, but presumably if I said

AIDS is easily caught from mosquitos, because Masters et al. say so

this would be an example of what they have in mind. Would it be a fallacy for me to do that? I grant that it would be "inadequate," if this means that I would be disingenuous, even misleading, if I pretended that there was no controversy and/or that I would be ripe for contestation by someone citing other experts with the contrary view. My argument would be weak because it would be easily countered, it would or should certainly "fail to settle the issue." But does that make it fallacious? Compare this case with a case of unproblematic appeal to authority; say I claim

AIDS is caused by a virus, because Masters et al. say so?

This is just the kind of argument which just about all text-book authors accept as being a non-fallacious appeal to authority. All the experts agree about the matter, or nearly. Actually even this example should be ruled out by the authors presently under discussion because there are a few experts like Peter Duesberg who dispute that AIDS is virological. This in itself shows that there is something wrong with claiming that a fallacy is committed by an example where there is no expert unanimity. There never is. Clearly I might be wrong in either of these cases, or even in the unlikely case of unanimity, since sometimes the experts are all wrong, this type of argument is never conclusive. But why would one be a fallacy and the other not? Would the latter argument somehow become a fallacy if suddenly Duesberg's view became prevalent? Surely the type of argument would not have changed.

To sum up, the examples given prove to be: two arguments bad through having a false premise, one not an argument at all, one an argument weak through vagueness, one an argument bad only in the way that any piece of testimony can turn out to be unreliable, and one an argument which is simply weak but not fallacious. The examples given in logic texts all seem to be like these! Either they 
are not arguments at all, or they are not bad arguments, or if they are bad, they are bad because of a false premise or presupposition. (The examples alluded to by Copi and Cohen-no argument is actually given-are testimonials and Einstein on politics: they clearly take the fallacy to be just use of a non-authority as if an authority, which is the false premise case.)

\section{[c] Arguments Given for Fallaciousness are Poor}

Reasons have been put forward why appealing to authority is or can be fallacious, but they are not very convincing.

Appealing to authority is sometimes said to be irrational. Irrationality is a lot broader than the committing of fallacy, and some kinds of irrationality positively preclude fallacy (see Coleman [1996]). We need a specification of what is irrational about it. One common suggestion is that one is substituting authority for evidence, and this is irrational. Such a suggestion presupposes that citing authority is not giving evidence, and this seems hard to square with accepting that sometimes it is a good way to argue. Either argument requires giving evidence, in which case if argument from authority is sometimes not fallacious it must give evidence; or else, as 1 would say, argument requires giving reason to believe which may be evidence but need not, as in the case of argument from authority. Either way this provides no reason for calling argument from authority a fallacy. One certainly is substituting authority for evidence if we take the narrow construal of what is evidence, but that's the point of the exercise; the question is precisely whether this is at least sometimes the rational thing to do, and accepting argument from authority as sometimes non-fallacious is to say that it is. So this suggestion just begs the question.

Another suggestion is that argument from authority forecloses debate, which is irrational (see Cederblom and Paulsen [1988]). This also seems to beg several questions: Is it not rational to close debate? Does appealing to authority foreclose debate? Does using 'foreclose' rather than 'close' not falsely assume that debates have a natural closing point? In fact, argument from authority need not close debate; what often happens is that the topic of debate shifts from the original claim to the expertise of the claimant. This is hardly irrational; we see it happening frequently in courts of law when expert witnesses are being used: the opponent will dispute the fact, extent or nature of the witness' expertise. It is true that the debate cannot be about the evidence for a claim if that evidence is not put forward, and it is also true that historically, appeals to authority have been used to avoid considering other evidence, but nothing indicates that this is intrinsic to its use. 'In any case, authority can be and often is pitted against authority, hardly closing debate.

Again, Salmon [1989: 355] says "To argue that a conclusion is correct merely because some authority figure accepts it is fallacious." Such a way of putting things is ambiguous between "arguing $p$, because $E$ accepts it" - i.e. going in for arguing $p$, for that reason - and "arguing [p, because $E$ accepts $p]$ ", i.e. arguing that $E$ 's acceptance is the reason, the explanation, for p's being so. This 
simply confuses the knowledge of the fact and the knowledge of the reasoned fact, as Aristotle puts it. That some authority accepts a fact is a good, though defeasible reason to believe it; but it does not of course explain why it is so. $p$ is rarely correct as a result of E's thinking it so. Other reasons for believing $\mathrm{p}$ might make plain why it is so, but this does not mean that authority cannot show it to be so. What "arguing $[p$, since $E$ accepts $p]$ " means is never " $p$, merely because $E$ accepts $p$ " so Salmon is engaging in travesty to report this form of argument in these terms.

These attempts to argue that appealing to authority is irrational are not very convincing ways to show that it is a fallacy. The other main argument is commonly implied in the course of discussion of examples: the fact is that such arguments are not conclusive: the desired conclusion could be false even though the premises are true. Despite what authors say a fallacy is, this tends to become the test for it. This "test" is applied to examples of other alleged fallacies too; and if one examines what is said about other fallacies one finds that quite a few are also claimed to be only sometimes fallacious, and that the examples given of other alleged fallacies are also frequently not even arguments, not bad arguments, or if bad are bad for reasons other than the one alleged. This all suggests that it is important to examine what exactly a fallacy is said, in general, to be. I will not go into this matter here because there is a long and complicated historical story to be told; although this is particularly relevant to explaining why and when it has been claimed that there is a fallacy of arguing from authority - since, and consequent on, the successful struggle of science to wrest intellectual authority from the Church - in this paper I confine myself to arguing that there is no such fallacy. I will take up these related issues on another occasion.

\section{[d] The Enthymeme Approach is Unprincipled}

Since all accounts agree at some point that not every argument from authority is fallacious, let us return to the idea of a part-time fallacy. In the journal literature some attempt has been made to determine when an argument of this kind is acceptable and when not, by identifying implicit premises for the "true form" of this type of argument, any of whose breach can lead to a "fallacious" use. The idea of treating argument from authority as an enthymeme is a natural one as I said at the beginning.

A says p, sop

is commonly cited, though the real form of the argument is

A says $p, A$ is authoritative on such things, so $p$.

But I want to contrast this recognition of a commonly suppressed premise with a strategy followed by some writers, for example Woods and Walton [1979a,b], which I think is misguided. It consists in attempting to identify a list of conditions which must be met if argument from authority is to be good, and building them into the form of the argument as further suppressed premises. The idea is that the real form of argument from authority is something like

1. $E$ is an expert on domain $D$ 


\section{E says $p$}

3. $p$ is in $D$

\section{Other experts say $p$ too}

5. p does not conflict with available "objective" evidence.

So plausibly, $p$.

The idea is that if, and only if, all these supplementary premises hold, the argument is good.

I have three objections to this. First, this kind of attempt to give a form for argument from authority is wrong-headed since it subscribes to the mistaken idea of formal logic that underneath the manifest argument there is a better one trying to get out. Second, I doubt whether clauses 4 and 5 reflect conditions which argument from authority need satisfy. 1 have argued against 4 already and 1 will make two points briefly against 5 . First, 'objective' begs many questions if the shudder-quotes are dropped, and 'objective evidence' presupposes or insinuates that testimony is not evidence, an idea which 1 have questioned already and which is explicitly disputed by some writers [Coady 1992, Hardwig 1985]. (Woods and Walton write 'direct evidence' but I don't know what that is; Walton [1989a p61], writes 'objective'.) Further, there are certainly cases where one will rightly prefer the testimony of an expert which conflicts with so-called objective evidence, for example when having mechanical faults diagnosed. But thirdly, whatever the merits of these clauses, this general idea cannot in any case serve the purpose of pinning down in what exactly consists the fallacy of argument from authority, since if it were successful it would turn every case of a bad argument from authority into an argument with a false premise. But a fallacy is not an argument with a false premise, but an argument in which the support offered by the premises to the conclusion is delusory. At least, that is what logicians generally claim (including our example text-book authors), because it is part of the standard account that logic is about the evaluation of entailments, not of premises.

Nevertheless, let us put aside the issue whether we should allow that a fallacy may be a kind of false premise because even if we do, there is a deeper problem with this kind of account. The list of allegedly implicit premises of Woods and Walton roughly corresponds to the lists of varieties of the fallacy, or ways to argue fallaciously, of textbook authors like Barry and Rudinow or Engel, or the lists of conditions for acceptable appeal to authority of other authors like Salmon, or the rather interesting list of test questions proposed by Ennis [1974] to ask in deciding of some testimony if one should accept it. But what is common to all of them is the lack of any reason for supposing that such an account is complete: on what basis can it be claimed that these and only these are the ways you can commit this fallacy? Or that these and only these are the conditions which must be satisfied or these and only these the suppressed premises that must hold? These writers all just produce their lists with no attempt to assure us that there are no other ways to go wrong, no other missing premises or conditions to satisfy. Perhaps this reflects the general shapelessness of discussions of fallacy, but it is not conducive to confidence since the lists all differ from one another. I present in Part 3 what I think is a better suggestion. 


\section{[e] Walton 1989}

Walton's discussion of argument from authority in [1989b] seems to me to improve on his earlier enthymematic approach. He discusses examples of the various kind of flaws which argument from authority can have some of which we have already seen: the Einstein syndrome, the lack of citation, the advertising testimonial, the conflict of experts, interpreting what they say. He refrains in most cases from saying that a fallacy is committed, and avoids talking about "varieties of a fallacy," as Barry and Rudinow do. Rather he proposes a list of questions to ask (rather like Ennis's) and writes of questioning an argument, giving it little weight and so on, rather than dubbing it a fallacy. This general idea of "argument criticisms" rather than fallacies is the right direction to go.

However Walton still wants there to be fallacy of arguing from authority, and it is interesting to see how he finds one. He has taken up from Hamblin's historical discussion the need to go back to Locke, and asserts in his introductory remarks that "Locke did not claim that all appeals to authority in argumentation are fallacious" [1989:173]. Locke called appeal to authority argumentum ad verecundiam (appeal to shame) because he was indeed concerned with intimidatory tactics in debate. Walton now identifies the fallacy in argument from authority as trying to use an appeal to authority to silence opposition.

I have three objections to this move. First, in point of fact Locke did not just not claim that not all arguments from authority are fallacious; he didn't claim that any were fallacious. He does not use the term fallacy in the relevant passage at all. Walton is being at least misleading in suggesting that he does. Second, in order to call a fallacy the practice which he has in mind, Walton defines fallacy [1989b: 19] as "important kinds of error or deceptive tactics of argumentation." As far as I know such a dichotomous definition is peculiar to Walton, although it is related to that of van Eemeren and Grootendorst (which I discuss next), through the notion of argumentation as reasoned dialogue. 1 am not suggesting that we do not want systematic discussion of deceptive tactics in argumentation, we do; but it seems to me very odd to describe the tactic in question as a fallacy. The attempts to cow the opposition in the examples given by Locke and the Port-Royal Logic, like

He is of high birth, therefore what he advances is true

rely at least as much on prestige, wealth, social position and in general political authority (which Walton wrongly dismisses as irrelevant [1989: 174]), as they do on alleged cognitive authority. One can criticize someone who acts so for hectoring or browbeating or even, though l'd prefer not to use this myself, for sophistry. But fallacy is surely at minimum some kind of error. If not, why doesn't Walton want to call all the other kinds of criticizability of arguments fallacies too? Finally, someone who tries to cow the opposition may well not be trying to or succeeding in deceiving them at all. The various churchmen who cited the authority of Aristotle and the Bible to Galileo were not trying to deceive him but to shut him up. 


\section{[f] van Eemeren and Grootendorst's Speech Act Approach}

These authors have tried to conceptualise "argumentative discussions" as dialogues consisting of various specifiable kinds of speech act organised in a specifiable way into a complex structure. They give a lengthy list of rules ideally governing such discussions (seventeen, most with subclauses) and in a bold stroke propose to replace the traditional mess about fallacies by declaring that a fallacy is any breach of any of these rules governing reasoned dialogue. This proposal has two great merits: it recognizes that many flaws in arguments are not really in them but in their context, and it recognizes that argument flaws come in many different kinds.

I have a number of reservations about their overall scheme which I will discuss on another occasion (Coleman, forthcoming) because their approach is complex and subtle. All that I want to argue here is that this characterization of fallacy as a breach of a rule of reasoned dialogue is of little help for our present problem. In their [1987], which introduces a slightly different formulation of what the rules of rational discussion are, arguing from authority is simply declared to be an inappropriate method of argumentation, which therefore breaches a rule banning such methods. But $I$ don't think that this will do, since it doesn't allow for the generally accepted fact that there are good cases of such argument. Further, unsuitability is a rather vague property which would need to be made considerably more specific to discriminate among appeals to authority and to explain why some are unacceptable.

\section{A Speech Act Analysis of Arguing from Authority}

I suggest that a speech act analysis of arguing by appeal to authority might be more systematic than the extant discussions. Such an analysis will make plain two dimensions of systematicity in the variety of ways in which argument from authority can go wrong without being fallacious, some of which we have seen in the examples discussed above.

Argument from authority is a doubly complex speech act because on the one hand it involves its utterer in arguing, which is itself already a complex speech act, and second because it involves the utterer in reporting someone else's attestation, which is a kind of indirect speech act (indirect in the sense of indirect or reported speech, not the sense in which Searle writes of indirect speech acts ${ }^{4}$.)

\section{Argument from Authority as a Speech Act}

Here is my suggestion.

First, to argue is already a complex speech act:

$W$ argues to $R$ for $p$ on the basis of $q$ if

[i] W asserts $q$ to $R$; [ where $q$ may be several premises]

[ii] W asserts $p$ to $R$; 
and [iii] $W$ indicates to $R$ that $q$ is reason to accept $p$.

Second, arguing from authority is a particular kind of arguing:

$W$ argues to $R$ for $p$ by appeal to the authority of $E$ by arguing thus

[ia] $W$ asserts to $R$ that $E$ attests to $p$ and [ib] $W$ asserts that $E$ is expert for $\mathrm{p}$;

[ii] $W$ asserts $p$ to $R$;

and [ii] $W$ indicates to $R$ that [E attests to $p$ and $E$ is expert for $p$ ] is reason to accept $p$.

The global speech act of argument from authority thus has five constituent speech acts. They are:

three assertions,

[1] $\mathrm{W}$ asserts that $\mathrm{E}$ attests to $\mathrm{p}$;

[2] $W$ asserts that $E$ is expert for $p$;

[3] $\mathrm{W}$ asserts that $\mathrm{p}$;

an attestation,

[4] E attests to $p$;

and an indication,

[5] $W$ indicates that [ $E$ attests to $p$ and $E$ is expert for $p$ ] is reason to accept p.

These five compose the whole complex speech act argument from authority, which is itself a sixth speech act, one of argument. Thus we have in a case of argument from authority six speech acts of four different kinds, namely assertion, attestation, indication and argument.

According to the theory of speech acts, all linguistic acts, whether making a definition or marrying two people or argument from authority, have a set of felicity conditions which provide natural kinds of possible ways they can go wrong.

The felicity conditions on any speech act originally given by Austin are these:

A1: There must be conventional/institutional setting and procedure involving a certain kind of utterance for effecting the speech act.

A2: The participants must all be suitably entitled for their roles.

B1: The procedure must be done properly.

B2 The procedure must be done completely.

$\Gamma 1$ : Participants must have the right intentions.

Г2: Participants must act appropriately afterwards.

(These are vague and overlapping but will suffice for present purposes. The points I want to make will survive an improvement to the analysis of felicity conditions.)

Each of the five acts involved in argument from authority will have felicity conditions of these six kinds, five local sets for the constituent speech acts and 
another global set for the whole act of argument. So there are thirty-six ways, not all equally important no doubt, in which the speech act of argument from authority might go wrong. And each of these will itself be possible in various ways. None of them deserves to be called committing a fallacy, but fortunately in order to see that we shall not need to look at all thirty-six of them in detail. Instead I shall argue in turn for some simple consequences of argument from authority's being a speech act, of its being a complex speech act, and of its being a speech act of argument.

\section{Implications of Argument from Authority Being a Speech Act}

The prevalent uncertainty about the role of deception in fallacy seems to me to have a rather simple explanation. If we think of an argument as a speech act and not as a mere propositional structure then there can be an uncertainty as to whether it is $\mathrm{W}$ or $\mathrm{R}$ or both that is mistaken when a fallacy is committed. The result of abstracting from dialectical contexts is to remove any possibility of anyone being deceived other than a transcendental ego contemplating a propositional structure. Of course, this point has been made before in other ways by various writers urging a dialectical analysis of argument.

The speech act perspective provides two further illuminations of the extant discussions of argument from authority. First, it is general feature of speech acts that they presuppose such things as sincerity as part of condition $\Gamma 1$. Not all do of course, but assertion and attestation do. There is no reason whatever to single out citing an expert with an axe to grind as committing a variety of a fallacy; if the cited expert was not sincere in attesting to $p$ then that attestation is infelicitous and inevitably the complex speech act of which it forms a part will be too. But even if this attestation were not put to use in argument, it would still be flawed by insincerity and just this flaw could be pointed out anyway. A fallacy is surely a flaw in arguing; a flaw which can occur even when one is not arguing should not be called a fallacy even when one is. Or perhaps better, before I am accused of a fallacy myself, I should say that when we say that a fallacy is a flaw in arguing we ought to mean a flaw which is a flaw in the arguing per se. Otherwise we shall have to start counting stuttering and muttering as fallacies, too.

Again, the requirements that the procedure for argument from authority be carried out completely and correctly are general requirements on speech acts. conditions B1 and B2. So citing authorities too vaguely to enable checking up-a commonly claimed "variety" or "way" of committing the "fallacy" of arguing from authority - is just a particular form which breaching these requirements can take for this particular speech act. The same point applies here too, that we should not be calling a fallacy what may be a flaw in arguing but which can equally be just a flaw in an assertion-or even a curse or an apology. 


\section{Implications of the Complex Structure of Argument from Authority as a Speech Act}

Let us now consider some implications of the complexity of argument from authority as a speech act.

The first is that the textbook obsession with so-called "testimonials"-wellknown people praising products in advertisements-actually confuses two different speech acts. Testimony (see Coady 1992) is not appeal to authority at all, it is an exercise of authority: in argument from authority, $W$ makes use of a prior testimony by $\mathrm{E}$, someone different. Don Meredith may be arguing if he is offering viewers reasons to buy tea-bags in his ads for them but he is not arguing by appeal to authority since it would have to be his own authority he would be appealing to. To speak authoritatively is not the same thing as the appeal to authority-it could not be since the point of appealing to authority is to back up what you say with what someone weightier says.

Second, there are many possible flaws in argument from authority not remarked on in textbooks.

\section{For example if I claim}

I am very wise. I say so, and I am expert on myself,

then if the second premise is true then I am speaking authoritatively but I am not appealing to authority. I am not usually entitled to appeal to myself as authority (pains being, controversially, a possible exception). Many other novel ways to botch appealing to authority can be devised.

Third, the various different so-called varieties of the fallacies of argument from authority, and problems about the use of experts discussed in the literature, can be systematically attributed to failures of the various conditions on the various constituent speech acts. We have already seen how breach of the fifth condition through insincerity can invalidate the cited expert attestation and vitiate the argument. Recall that in every speech act, one of the felicity conditions (A2) is that the participants must be appropriately entitled to take their roles - for example not just you or I can conduct a wedding or launch a ship. This applies equally to the assertions by $W$ of E's expertise and E's having attested to $p$. Consider first the question when $W$ is entitled to assert that $E$ attests to $p$.

First, $W$ must be able to back this claim up, so must have available what we might call a citatory trail. W must be able to supply potential objectors with means to verify that $E$ did indeed attest to $p$. This in turn typically presupposes the existence of writing, archives, bibliographical conventions and a whole social infrastructure organised around the practice of serious public depositions such as Aristotle's and Einstein's works. Although argument from authority is used in the court situation using verbal testimony from authorities, this is not the typical situation. Rather, typically argument from authority involves citation of published statements. (In any case court records are kept to overcome this difference.)

A second implication of the entitlement requirement, or perhaps of the proper execution requirement (B1) depending on the case, is that $\mathrm{W}$ should not be 
misinterpreting or misquoting the expert. This is a common problem which many texts quite rightly discuss, though far too many call it a fallacy. It is not a fallacy because once again precisely this flaw can arise in citing for non-argumentative purposes.

In argument from authority, $W$ also asserts that $E$ is expert for $p$. Such an assertion can also be flawed in any of the usual six dimensions. W must be entitled to assert that $E$ is expert for $p$. If we ask what such entitlement consists in, we open a large can of worms. W must have some grounds for believing that there is some domain of expertise to which $p$ belongs and that $E$ is qualified with respect to that domain. What counts as a domain of expertise is a difficult question - though we should not proceed, as do many authors, to identify argument from authority with appealing to so-called technical expertise. Often people are qualified to attest to matters through mere position or accident. For example:

Tom's on the phone from Adelaide; he says it's raining there,

is quite sufficient to justify my claiming that it is raining in Adelaide and is a genuine if humble argument from authority. In most circumstances I would have good reason to think that Tom was qualified to attest to the weather in Adelaide if that is where he was, and I was not. But of course the difficult cases are those where some kind of technical expertise is claimed. Are there really experts on insanity? What kind of thing do they know? How do you identify such a person? There is a lot of discussion of this kind of question in the literature, though it doesn't come to very useful conclusions. My point here is simply that unsatisfactory answers to such questions in a particular case of argument from authority are no reason for crying 'fallacy', they are once again just evidence of the enormous complexity of argument from authority as a speech act. In many cases there is a quite crucial role of documentation in the establishment of domains of expertise and the credentials of authorities. This brings out again the importance of writing for the social practice of argument from authority.'

\section{Implications of Argument from Authority Being a Speech Act of Argument}

I have been using a general argument against calling various possible tlaws in argument from authority fallacies, which consists in pointing out that they can obtain when one of the constituent speech acts is used for non-argumentative purposes. This provides us with one positive argument for there being no such fallacy. If we now consider the implications of the fact that argument from authority is a speech act of argument we can make clear another positive argument. It is this: if we are going to identify any way in which argument from authority in going wrong is a fallacy it will have to be in virtue of argument from authority's being a speech act of argument; and we know that it cannot be in asserting the premises that one may make a fallacy, only in the further claim that they support the conclusion. Thus it can only be in the conditions on the embedded speech act of indication that we need look for fallacy. Flaws in the acts of assertion of the premises by $\mathrm{W}$ and the doubly embedded act of attestation by 
$\mathrm{E}$ are problems with the premises and cannot be the source of fallacy (though they can be and often are the source of other ways of going wrong).

\section{Felicity Conditions for Argument}

$W$ argues for $p$ to $R$ if

[i] $W$ asserts to $R$ that $q$;

[q may be several premises]

[ii] $W$ asserts to $R$ that $p$;

[iii] $W$ indicates to $R$ that $q$ is reason to accept $p$.

Indication is a speech act which is in general less explicit than is assertion. In many of its uses its point depends on its being less than fully explicit (here I part company with Searle's expressibility principle). However this is not the case in argument, where within reason the more explicit the logical signposting the better: to say ' $q$, so $p$ ' is clearer and generally better than a mere ' $q ; p$ ', though many arguments are given without explicit warranting connectives. So I will amend this account for present purposes and replace clause [iii] with

[iii*] $W$ asserts to $R$ that $q$ is reason to accept $p$ with the caveat that what counts as assertion must be interpreted reasonably charitably here.

Felicity conditions for arguing are then:

[11] The assertion of the premises must be felicitous.

[12] The indication or assertion of the support-claim must be felicitous.

[13] The assertion of the conclusion must be felicitous.

\section{Flawed Argument}

We have two constituent acts which can go wrong independently corresponding to the usual distinction between arguments with bad premises and those with bad inferences. And there is a third possibility because the speech act of argument is a complex one constituted by the (at least) two assertions: it is not simply a sequence of assertions.

[11 flaws] Any argument in which the assertion of the premises is infelicitous is ungrounded-the premises are unacceptable in some way, not necessarily through falsity.

[12 flaws] An argument in which the indication of support goes awry may or may not be a non sequitur. But even a non sequitur is not yet a fallacy, so we need to consider just what felicity condition's failure might make flawed supportindication into a fallacy. Let us leave aside for the moment contexts in which indicating support is not a socially recognised practice (failure of felicity condition $\mathrm{A} 1$ ); in any case one would hardly speak of fallacy then. Perhaps we can see circumstances in which A2 might fail, a participant's not being entitled to make indications, for example witnesses are just supposed to answer questions but not draw inferences from these answers. But no fallacy is involved in such 
over-eagerness. Failing to carry out the procedure of indication properly or completely (B1 or B2) may well make the argument weak because the audience is not clear exactly what the argument is. But this is still not even a nonsequitur. Finally we come to the possibility that the participants' attitudes or actions are inappropriate and it is only here that the possibility of fallacy may arise. Only if $\mathrm{W}$ is mistaken in believing that the premises offer support for the conclusion do we have a nonsequitur and possibly a fallacy.

[13 flaws] Interestingly, there is a second way in which a fallacy might possibly arise, namely by defective assertion of the conclusion. For example, if there is some difference between the premises asserted and those believed by $\mathrm{W}$ to give the conclusion support. Asserting a conclusion is not just asserting some claim, but a claim as a conclusion.

We have then two candidates for the fallacy of arguing by appeal to authority: mistakenly believing that the premises support the conclusion, and confusing the issue somehow between premises and conclusion. This latter will be some classical fallacy such as irrelevant conclusion or equivocation-and thus not that other alleged fallacy, appealing to authority. So we are reduced to asking if there is a mistake which consists in believing

$[*]$ that the premises [E attests to $p$ and $E$ is expert for $p]$ if irue give support to the conclusion $p$.

And the answer is simply no, because virtually everyone admits that sometimes argument from authority is a good argument. Consider for example the kind of argument allegedly put to Galileo:

Aristotle says that the earth does not move, so the earth does not move.

The argument which was actually used in the Galileo affair and related disputes is actually much better represented as

The Bible says that the earth does not move, so the earth does not move. which is enthymematic for

The Bible says the earth does not move and the Bible is the word of God. so the earth does not move

and this in turn seems to have been taken as equivalent to

God says the earth does not move, so the earth does not move

This argument must surely be good: what better reason could one have for accepting $p$ than God's asserting it? Of course, the truth of the premise presupposes the existence of God with the usual Christian properties, but if it is true it is surely completely unthinkable that the earth does not move should be false and that this should not be a good argument for it.

So that it cannot be this belief $\left[{ }^{*}\right]$ which is at fault. On the contrary, if $[E$ attests to $p$ and $E$ is expert for $p]$ is true then it does give support to $p$. Those premises, if true, do give support to that conclusion. I do not claim that they show it to be true, only that they support it: they give one good reason to believe it. Arguing from authority is not a conclusive form of argument. Of course, the premises only give any support to the conclusion if they are true; but this is equally true for demonstrative arguments like, 
if it is night, it is light, it is night, so it is light, which has an inference of the form modus ponens, the paradigm valid form of inference. To say it is valid, however, is not to say that the premises of such an inference do support the conclusion but only that if they were true they would support the conclusion; in fact if they were true they would support it so well that the conclusion must also be true. That is what validity means. The point logicians emphasise, that the inference can be good while the premises are not, as in this example, applies just as well to non-conclusive arguments like argument from authority. The inference can be good, while the premises are wanting, as indeed they often are.

There is another way to put the point. It is generally agreed that some arguments of this form are good. But they cannot be good if the principle of inference on which they rely is bad. Since there are two ways an argument can be bad, there are two virtues it must have if it is to be good, good premises and a good principle of inference. Therefore the principle of inference of a good argument is good. But some arguments from authority are good arguments. Therefore the principle of inference of argument from authority is good.

What the preceding discussion shows is that among the very many ways in which the speech act of arguing by appeal to authority could go wrong, only one is even a candidate for being a fallacy; but precisely that way is not a way to go wrong at all. So although fallacies like irrelevant conclusion can be committed in argument from authority, there is no fallacy of argument from authority.

In summary, the case for thinking there is a fallacy of argument from authority is weak, resting on confused presentation, non-exemplary examples, and feeble arguments, while a speech act analysis of argument from authority shows that among the many ways it might possibly go wrong, the only one that might constitute fallacy is actually a good principle of inference. So there is no such fallacy as argument from authority.

\section{Notes}

'This is not a very good definition but its defects don't affect my arguments in this paper.

? I take as exemplary two texts used in the two South Australian Universities other than my own at the time of writing.

${ }^{3}$ This may seem to assume that considering the evidence would overthrow the appeal to authority. It would perhaps be better to say that appealing to authority may sometimes lead one to disdain the use of evidence. The famous cases. like Galileo's, were like that, the fault was in the weighing of different kinds of evidence. But no doubt this blind and unmerited substitution of one kind of evidence for another explains much animus against appeal to authority.

*I am adopting the original analysis of Austin [1972]: I do not agree with some authors that Searle's revisions count as improvements, but nothing much turns on this for present purposes.

"In fact I think it is quite essential to the existence of this particular kind of argument. and I would prefer to write of "language acts' not 'speech acts". but I will not pursue this complex issue here. This is part of the reason why I have been content with Austin's formulation of 
felicity: we really need to develop an account of "speech" acts which takes documentation seriously. This is a large task.

\section{References}

Austin J [1972] How to do things with words Oxford: Oxford University Press.

Barry $V$ and Rudinow J [1989] Invitation to critical thinking Fort Worth: Holt, Rinehart and Winston.

Cederblom J and Paulsen W [1988] "Making reasonable decisions in world of experts" in Govier [1988].

Coady [1992] Testimony Oxford: Oxford University Press.

Coleman E [1996] "Fallacy Irrationality Mistake in P Hager and J Roe, eds. Proceedings, Fourth National Reasoning Conference, Sydney: UTS.

Coleman E [1997] "Fallacies: there are and there aren' $t$ " forthcoming.

Copi 1 [1961] Introduction to logic, $2^{\text {hi }}$ ed. New York: Macmillan.

Copi I \{and C Cohen\} [1990] Introduction to logic, $8^{\text {th }}$ ed. New York: Macmillan.

Eemeren $\mathrm{F}$ and Grootendorst $\mathrm{R}$ [1984] Speech acts in argumentative discussions Dordrecht: Foris.

Eemeren F and Grootendorst R [1987] "Fallacies in pragma-dialectical perspective" Argumentation 1: 283-301.

Ennis R H [1974] "The believability of people" Educational Forum 39:347-54.

Govier $\mathrm{T}$ [ed.] [1988] Selected issues in logic and communication Belmont CA: Wadsworth.

Hamblin $\mathrm{CH}[1970]$ Fallacies London: Methuen.

Hardwig J [1985] "Relying on experts" in Govier [1988] = "Epistemic dependence" $J$ Phil $82.7: 335-49$.

Locke J [1961] An essay concerning human understanding, ed. Yolton, London: Dent.

Salmon M [1988] Introduction to logic and critical thinking, $2^{\text {kt }}$ ed., San Diego, Ca.: Harcourt Brace Jovanovich.

Walton D [1989a] "Reasoned use of expertise in argumentation" Argumentation 3: 59-73.

Walton D [1989b] Informal Logic Cambridge: Cambridge University Press.

Willard C [1990] "Authority" Informal Logic 12.1: 11-22

Woods $\mathrm{J}$ and Walton D [1989] Fallacies: selected papers Dordrecht: Foris.

Woods J and Walton D [1979a] "Argumentum ad verecundiam" ch2 of Woods and Walton [1989].

Woods J and Walton D [1979b] "What type of argument is Ad verecundiam?" Chapter 14 of Woods and Walton [1989].

EDWIN COLEMAN PHILOSOPHY DEPARTMENT UNIVERSITY OF MELBOURNE PARKVILLE, AUSTRALIA 3052 